\title{
Assessment of Right Ventricular Function Using Strain and Strain Rate in Patient with Acute Anterior ST Segment Elevation Myocardial Infarction
}

\author{
Mahmoud Hamed Hagagi*, Said Shalaby Montaser², Ahmed Mohamed Emara², \\ Mohamed Osama Taha ${ }^{2}$ \\ ${ }^{1}$ Department of Cardiology, National Heart Institute, Cairo, Egypt \\ ${ }^{2}$ Department of Cardiology, Faculty of Medicine, Menoufia University, Al Minufya, Egypt \\ Email: *mahmoudhaggag512@gmail.com
}

How to cite this paper: Hagag, M.H., Montaser, S.S., Emara, A.M. and Taha, M.O. (2020) Assessment of Right Ventricular Function Using Strain and Strain Rate in Patient with Acute Anterior ST Segment Elevation Myocardial Infarction. World Journal of Cardiovascular Diseases, 10, 337-346.

https://doi.org/10.4236/wjcd.2020.105032

Received: February 8, 2020

Accepted: May 25, 2020

Published: May 28, 2020

Copyright (c) 2020 by author(s) and Scientific Research Publishing Inc. This work is licensed under the Creative Commons Attribution International License (CC BY 4.0).

http://creativecommons.org/licenses/by/4.0/

\begin{abstract}
Introduction: Anterior ST-segment elevation myocardial infarctions (STEMI) are those involving the anterior ECG leads of the heart as a result of transmural ischaemia. They can be subdivided according to their extension into anteroseptal and anterolateral infarctions. Objective: The aim of this study is assessment of right ventricular function using strain and strain rate imaging in patients with anterior ST segment elevated myocardial infarction (STEMI). Methods: This prospective study was conducted on 35 patients with anterior ST segment elevated myocardial infarction (STEMI) who were admitted to ER and CCU department in National Heart Institute from May 2018 to May 2019. Results: Comparison between groups regarding longitudinal strain showed that there is highly statistically significant difference between them in lateral wall (all segments), septum (all segments) and global LS of right ventricle. Comparison between studied groups regarding circumferential strain revealed that there is highly statistically significant difference between them in all segments of right ventricle. Conclusions: Strain and strain rate imaging are feasible and reproducible tools in assessment of right ventricular function in patients with anterior ST segment elevated myocardial infarction (STEMI).
\end{abstract}

\section{Keywords}

Myocardial Infarction, STEMI, Strain and Strain Rate Imaging 


\section{Introduction}

Anterior ST-segment elevation myocardial infarctions (STEMI) are those involving the anterior ECG leads of the heart as a result of transmural ischaemia. They can be subdivided according to their extension into anteroseptal and anterolateral infarctions [1].

Assessment of left ventricular (LV) function has become standard practice after MI. It is known that the left ventricular function is a predictor of cardiovascular morbidity and mortality after MI [2]. In contrast, assessment of the right ventricular (RV) function after MI is still uncommon. Some studies suggest that $\mathrm{RV}$ function is an independent predictor of mortality and development of heart failure (HF) in patients with known LV dysfunction due to MI [3].

In practice, clinicians largely rely on non-invasive imaging methods for assessment of RV function. Two-dimensional (2-D) echocardiography is the mainstay for analysis of RV function, but recently alternative techniques have been proposed, including tissue Doppler imaging (TDI) techniques, three dimensional (3-D) echocardiography, magnetic resonance imaging (MRI) and speckle tracking echocardiography (STE) [4].

Speckle tracking allows the assessment of myocardial strain and strain rate. Myocardial strain is a dimensionless index of tissue deformation expressed as a fraction or percent change. Myocardial lengthening gives a positive and shortening gives a negative strain value. Strain rate (SR) measures the local rate of deformation per unit time. Two-dimensional (2-D) strain and strain rate (SR) analyses are valuable Doppler-independent techniques to obtain measurements of myocardial movement and deformation [5].

We designed this work to study the right ventricular function using echocardiographic 2-D speckle tracking in patients that experienced anterior ST segment elevation myocardial infarction (STEMI).

\section{Methods}

This prospective study was conducted on 35 patients with Anterior ST segment Elevated myocardial infarction (STEMI) who were admitted to ER and CCU Department in National Heart Institute from May 2018 to May 2019.

\subsection{Inclusion Criteria}

Patients, with STEMI with symptoms onset less than $12 \mathrm{~h}$, who underwent successful primary PCI in the first $24 \mathrm{~h}$ from hospital admission, were included.

Diagnosis of acute myocardial infarction was made on the basis of typical ECG changes (new ST-segment elevation at the J point in $\geq 2$ contiguous leads ( $\geq 0.2 \mathrm{mV}$ in $\mathrm{V} 1$ through $\mathrm{V} 3$ and $\geq 0.1 \mathrm{mV}$ in other leads)) and ischemic chest pain associated with elevation of cardiac biomarkers.

\subsection{Exclusion Criteria}

- Thrombolytic treatment within 24 hours. 
- Patients with preexisting severe depression of left ventricular systolic function $(\mathrm{EF}<25 \%)$, age younger than 18 years and bad echocardiographic windows.

Data were collected including history, general and full cardiovascular assessments. Investigations included ECG, coronary angiography and echocardiography including conventional echocardiographic measurements, tissue Doppler-Derived Strain and Strain-Rate Imaging and two dimensional (2-D) speckle tracking echocardiography for all patients.

\subsection{Tissue Doppler-Derived Strain and Strain-Rate Imaging}

Tissue Doppler imaging (TDI), also known as tissue velocity imaging (TVI), is currently accepted as a sensitive and sufficiently accurate echocardiographic tool for quantitative assessment of cardiac function. Several tissue Doppler velocity parameters appeared to be useful for the diagnosis and prediction of long-term prognosis in major cardiac diseases. Myocardial time-velocity curves can be obtained either online as spectral pulsed TDI, known as pulsed wave TDI (PW-TDI), or reconstructed offline from two-dimensional (2D) color coded TDI images, known as color TDI (C-TDI) loops [6].

\subsection{Two Dimensional (2-D) Speckle Tracking Echocardiography}

Three LV apical long axis views; apical four-chambers, two chambers, and apical three chambers views were acquired at frame rates ranging between 50 - 90 frame/s. Three consecutive cardiac cycles were acquired at end-expiration breath hold and digitally stored on CDs for offline analysis. In order to measure the timing of cardiac events, LV inflow (mitral) and outflow (aortic) velocities were recorded using pulsed-wave Doppler.

Using 2D strain software, the RV and LV endocardial borders of the endsystolic frame were manually traced. On the basis of this line, the computer automatically created a region of interest (ROI) including the entire transmural wall, and the software selected suitable natural acoustic markers (speckles) moving with the tissue for tracking.

\subsection{Statistical Analysis of Data}

The collected data organized, tabulated and statistically analyzed using statistical package for social sciences (SPSS) version 22 (SPSS Inc., Chicago, USA). For qualitative data, frequency and percent distributions was calculated. For quantitative data, mean, standard error (SE), minimum and maximum were calculated. Statistical significance was defined as $\mathrm{P}$ value $<0.05$.

\section{Results}

There was no statistically significant difference between two groups regarding neither demographic data as (age, sex) nor risk factors as (dyslipidemia, smoking, DM or HTN). Mean \pm SD of patients age $60.09 \pm 9.78$ VS $59 \pm 10$ years of 
control. Regarding percent of DM (28.6\% of patients VS $40.0 \%$ of control) (P-value 0.355$)$. Regarding percent of HTN (34.3\% of patients VS $24.0 \%$ of control) (P-value 0.391 ). Regarding percent of smoking (34.3\% of patients VS $36.0 \%$ of control) (P-value 0.891$)$. Regarding percent of dyslipidemia (20.0\% of patients VS 28.0\% of control) (P-value 0.470 ) (Table 1 ).

Comparison between groups regarding longitudinal strain showed that there is highly statistically significant difference between them in lateral wall (all segments), septum (all segments) and global LS of right ventricle. Regional strain of lateral wall (Mean \pm SD of patients $-13.91 \pm 2.80 \mathrm{VS}-28.30 \pm 0.82$ of control) (P-value $<0.001$ ). Regional strain of septum (Mean \pm SD of patients $-15.39 \pm$ $1.57 \mathrm{VS}-23.45 \pm 1.29$ of control) (P-value $<0.001$ ). Global longitudinal strain of $\mathrm{RV}$ (Mean \pm SD of patients $-14.65 \pm 2.04 \mathrm{VS}-25.88 \pm 0.63$ of control) (P-value $<0.001$ ) (Table 2).

Comparison between studied groups regarding circumferential strain revealed that there is highly statistically significant difference between them in all segments of right ventricle. Anterior circumferential strain (Mean \pm SD of patients $-14.57 \pm 1.63$ VS $-16.80 \pm 2.12$ of control) (P-value < 0.001$)$. Lateral circumferential strain (Mean \pm SD of patients $-13.60 \pm 2.67 \mathrm{VS}-16.16 \pm 2.70$ of control) (P-value $<0.001)$. Inferior circumferential strain (Mean \pm SD of patients -10.74 \pm 1.99 VS $-15.96 \pm 2.96$ of control) (P-value $<0.001$ ). Regional circumferential strain (Mean \pm SD of patients $-12.97 \pm 1.52$ VS $-15.98 \pm 1.06$ of control) (P-value < 0.001) (Table 3).

$100 \%$ of patients had significant lesion in left anterior descending artery and only $31.4 \%$ had significant lesion in LCX (left circumflex artery) while majority 68.6\% had no significant lesion in LCX (Figure 1 and Figure 2).

Table 1. Comparison between study groups regarding demographic data and risk factors.

\begin{tabular}{|c|c|c|c|c|c|c|c|c|}
\hline \multirow{2}{*}{ Patient's Data } & \multicolumn{2}{|c|}{ Patients } & \multicolumn{2}{|c|}{ Control } & \multicolumn{2}{|c|}{ Total } & \multicolumn{2}{|c|}{ Tests } \\
\hline & $\mathbf{N}$ & $\%$ & $\mathbf{N}$ & $\%$ & $\mathbf{N}$ & $\%$ & $t$ or $X^{2}$ & $P$-value \\
\hline \multirow{2}{*}{ Sex } & 16 & 45.7 & 10 & 40.0 & 26 & 43.3 & \multirow[b]{2}{*}{0.194} & \multirow[b]{2}{*}{0.660} \\
\hline & 19 & 54.3 & 15 & 60.0 & 34 & 56.7 & & \\
\hline \multirow[b]{2}{*}{ Age (years) } & \multicolumn{2}{|c|}{$39-74$} & \multirow{2}{*}{\multicolumn{2}{|c|}{$40-72$}} & & & & \\
\hline & \multicolumn{2}{|c|}{$60.09 \pm 9.78$} & & & & & 0.420 & 0.676 \\
\hline \multirow[b]{2}{*}{ Weight (kg) } & \multicolumn{2}{|c|}{$55-95$} & \multicolumn{2}{|c|}{$67-93$} & & & & \\
\hline & \multicolumn{2}{|c|}{$78.29 \pm 11.11$} & \multicolumn{2}{|c|}{$81.64 \pm 8.99$} & & & 1.246 & 0.218 \\
\hline DM & 10 & 28.6 & 10 & 40.0 & 20 & 33.3 & 0.857 & 0.355 \\
\hline Smoker & 12 & 34.3 & 9 & 36.0 & 21 & 35.0 & 0.019 & 0.891 \\
\hline HTN & 12 & 34.3 & 6 & 24.0 & 18 & 30.0 & 0.735 & 0.391 \\
\hline FH & 6 & 17.1 & 3 & 12.0 & 9 & 15.0 & 0.303 & 0.582 \\
\hline Dyslipidemia & 7 & 20.0 & 7 & 28.0 & 14 & 23.3 & 0.522 & 0.470 \\
\hline
\end{tabular}


Table 2. Comparison between study groups regarding longitudinal strain.

\begin{tabular}{|c|c|c|c|c|c|c|}
\hline \multirow{2}{*}{\multicolumn{2}{|c|}{ Longitudinal Strain }} & \multirow{2}{*}{ Groups } & \multirow{2}{*}{ Patients } & \multirow{2}{*}{ Control } & \multicolumn{2}{|c|}{ T-test } \\
\hline & & & & & $\mathrm{T}$ & P-value \\
\hline \multirow{8}{*}{ 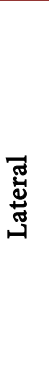 } & \multirow{2}{*}{ Basal } & Range & $-21.00-17.00$ & $-31.00--27.00$ & \multirow{2}{*}{11.162} & \multirow{2}{*}{$<0.001^{* *}$} \\
\hline & & Mean \pm SD & $-15.23 \pm 6.11$ & $-29.16 \pm 1.43$ & & \\
\hline & \multirow{2}{*}{ Mid } & Range & $-22.00--8.00$ & $-31.00--24.00$ & \multirow{2}{*}{20.130} & \multirow{2}{*}{$<0.001^{\star *}$} \\
\hline & & Mean \pm SD & $-14.14 \pm 3.21$ & $-28.60 \pm 1.89$ & & \\
\hline & \multirow{2}{*}{ Apical } & Range & $-23.00--5.00$ & $-30.00--24.00$ & \multirow{2}{*}{20.462} & \multirow{2}{*}{$<0.001^{\star *}$} \\
\hline & & Mean \pm SD & $-11.40 \pm 3.64$ & $-27.16 \pm 1.46$ & & \\
\hline & \multirow{2}{*}{ Regional } & Range & $-22.00--8.66$ & $-29.66--27.00$ & \multirow{2}{*}{24.897} & \multirow{2}{*}{$<0.001^{\star *}$} \\
\hline & & Mean \pm SD & $-13.91 \pm 2.80$ & $-28.30 \pm 0.82$ & & \\
\hline \multirow{8}{*}{ 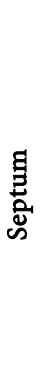 } & \multirow{2}{*}{ Basal } & Range & $-19.00--12.00$ & $-25.00--17.00$ & \multirow{2}{*}{9.219} & \multirow{2}{*}{$<0.001^{* *}$} \\
\hline & & Mean \pm SD & $-16.51 \pm 1.52$ & $-20.56 \pm 1.87$ & & \\
\hline & \multirow{2}{*}{ Mid } & Range & $-23.00--11.00$ & $-29.00--19.00$ & \multirow{2}{*}{10.653} & \multirow{2}{*}{$<0.001^{\star *}$} \\
\hline & & Mean \pm SD & $-15.77 \pm 2.50$ & $-23.44 \pm 3.07$ & & \\
\hline & \multirow{2}{*}{ Apical } & Range & $-21.00--11.00$ & $-28.00--21.00$ & \multirow{2}{*}{20.248} & \multirow{2}{*}{$<0.001^{\star *}$} \\
\hline & & Mean \pm SD & $-13.89 \pm 2.75$ & $-26.32 \pm 1.60$ & & \\
\hline & \multirow{2}{*}{ Regional } & Range & $-21.00--12.00$ & $-26.00--21.66$ & \multirow{2}{*}{21.041} & \multirow{2}{*}{$<0.001^{\star *}$} \\
\hline & & Mean \pm SD & $-15.39 \pm 1.57$ & $-23.45 \pm 1.29$ & & \\
\hline \multirow{2}{*}{\multicolumn{2}{|c|}{ Global LS of RV }} & Range & $-19.83--10.33$ & $-27.00--25.00$ & \multirow{2}{*}{26.562} & \multirow{2}{*}{$<0.001^{\star *}$} \\
\hline & & Mean \pm SD & $-14.65 \pm 2.04$ & $-25.88 \pm 0.63$ & & \\
\hline
\end{tabular}

Table 3. Comparison between study groups regarding circumferential strain.

\begin{tabular}{|c|c|c|c|c|c|}
\hline \multirow{2}{*}{$\begin{array}{l}\text { Circumferential } \\
\text { Strain }\end{array}$} & \multirow{2}{*}{ Groups } & \multirow{2}{*}{ Patients } & \multirow{2}{*}{ Control } & \multicolumn{2}{|c|}{ T-test } \\
\hline & & & & $\mathrm{t}$ & P-value \\
\hline \multirow{2}{*}{ Ant } & Range & $-18.00--11.00$ & $-21.00--13.00$ & \multirow{2}{*}{4.599} & \multirow{2}{*}{$<0.001^{* *}$} \\
\hline & Mean \pm SD & $-14.57 \pm 1.63$ & $-16.80 \pm 2.12$ & & \\
\hline \multirow{2}{*}{ Lat } & Range & $-21.00--6.00$ & $-22.00--10.00$ & \multirow{2}{*}{3.643} & \multirow{2}{*}{$<0.001^{* *}$} \\
\hline & Mean \pm SD & $-13.60 \pm 2.67$ & $-16.16 \pm 2.70$ & & \\
\hline \multirow{2}{*}{ Inf } & Range & $-15.00--6.00$ & $-23.00--12.00$ & \multirow{2}{*}{8.161} & \multirow{2}{*}{$<0.001^{* *}$} \\
\hline & Mean \pm SD & $-10.74 \pm 1.99$ & $-15.96 \pm 2.96$ & & \\
\hline \multirow{2}{*}{ Regional } & Range & $-16.00--9.30$ & $-18.33--13.55$ & \multirow{2}{*}{8.518} & \multirow{2}{*}{$<0.001^{\star *}$} \\
\hline & Mean \pm SD & $-12.97 \pm 1.52$ & $-15.98 \pm 1.06$ & & \\
\hline
\end{tabular}

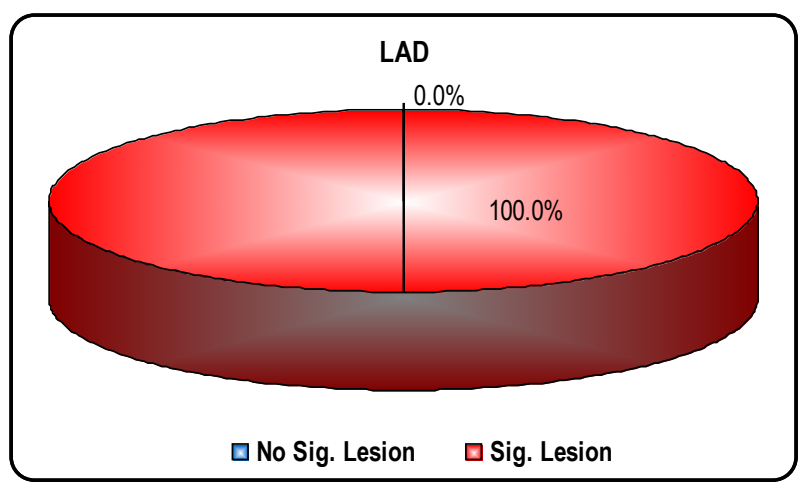

Figure 1. Distribution of significant lesions in left anterior descending artery. 


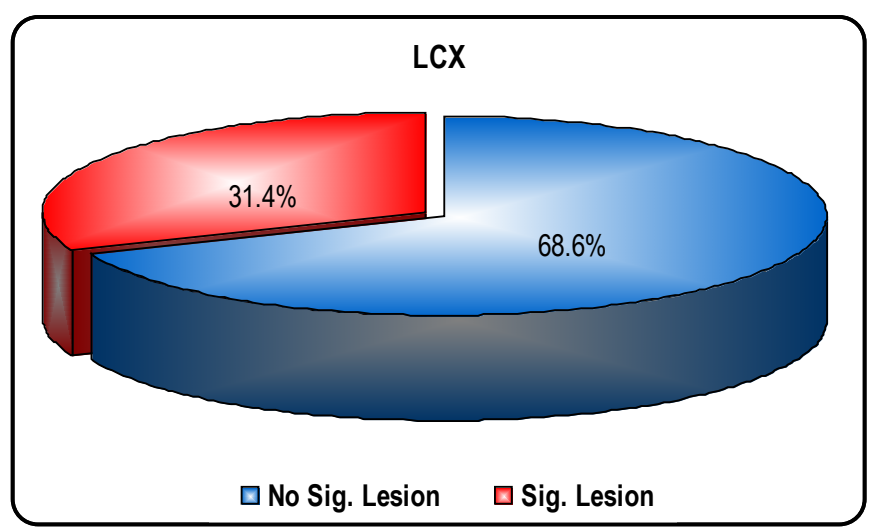

Figure 2. Distribution of significant lesions in left circumflex artery.

Correlation between the site of lesion and LAD (left anterior descending artery) and LCX artery with impaired right ventricle function found that there is statistically significant difference between mid segment (P-value 0.037) and apical segment (P-value 0.024) of lateral wall and LAD; also there is statistical significant difference between apical segments of the septum ( $\mathrm{P}$-value 0.040), while there is statistical significant difference between anterior ( $\mathrm{P}$-value 0.041), lateral (P-value 0.035), Inferior (P-value 0.003) and regional (P-value 0.003) parts of the right ventricle and circumflex artery (Table 4 ).

\section{Discussion}

ST-elevation myocardial infarction (STEMI) is characterized by a loss of contractile tissue and a change in ventricle geometry that causes substantial impairment of the ventricular systolic and diastolic functions [7].

RV-STEMI has been reported in 10 to $60 \%$ of patients with inferior STEMI. The co-existence of inferior STEMI and RV-STEMI has been shown to increase morbidity and mortality rates [8].

Speckle tracking allows the assessment of myocardial strain and strain rate. Myocardial strain is a dimensionless index of tissue deformation expressed as a fraction or percent change. Myocardial lengthening gives a positive and shortening gives a negative strain value. Strain rate (SR) measures the local rate of deformation per unit time [9].

Our study showed that demographic characteristics of the participants patients and control groups revealed that majority of cases were male $54.3 \%$, Mean \pm SD of age of cases is $60.09 \pm 9.78$ and in control is $59 \pm 10$ years old, Mean \pm SD of weight is $78.29 \pm 11.11$ and $81.64 \pm 8.99 \mathrm{~kg}$ in cases and control respectively, and there was no statistically significant difference between two groups regarding neither demographic data as (age, sex) nor risk factors as (dyslipidemia, smoking, DM or HTN).

This is coped with the study of Monaster et al. (2014) in which regarding demographics and risk factors of the study population, there were no significant differences between the studied groups [10]. 
Table 4. Correlation between site of lesion as regarding of LAD and LCX artery with impaired right ventricle function.

\begin{tabular}{|c|c|c|c|c|c|}
\hline & & \multicolumn{2}{|c|}{ LAD } & \multicolumn{2}{|c|}{ LCX } \\
\hline & & $\mathbf{r}$ & P-value & $\mathbf{R}$ & P-value \\
\hline \multirow{4}{*}{ 氶 } & Basal & 0.115 & 0.509 & 0.495 & 0.122 \\
\hline & Mid & 0.347 & $0.037^{\star}$ & 0.132 & 0.699 \\
\hline & Apical & 0.332 & $0.024^{\star}$ & 0.451 & 0.164 \\
\hline & Regional & 0.192 & 0.268 & 0.419 & 0.200 \\
\hline \multirow{4}{*}{ 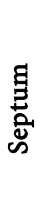 } & Basal & 0.232 & 0.181 & 0.229 & 0.498 \\
\hline & Mid & 0.098 & 0.575 & 0.013 & 0.970 \\
\hline & Apical & 0.349 & $0.040^{*}$ & 0.385 & 0.242 \\
\hline & Regional & 0.220 & 0.205 & 0.100 & 0.771 \\
\hline \multicolumn{2}{|c|}{ Global LS of RV } & 0.222 & 0.200 & 0.356 & 0.282 \\
\hline \multicolumn{2}{|c|}{ Ant } & 0.156 & 0.372 & 0.622 & $0.041^{\star}$ \\
\hline \multicolumn{2}{|c|}{ Lat } & 0.044 & 0.802 & 0.638 & $0.035^{*}$ \\
\hline \multicolumn{2}{|c|}{ Inf } & 0.184 & 0.291 & 0.797 & $0.003^{*}$ \\
\hline \multicolumn{2}{|c|}{ Regional } & 0.108 & 0.537 & 0.806 & $0.003^{*}$ \\
\hline
\end{tabular}

The present study found that there is highly statistically significant difference between them in lateral wall (all segments), septum (all segments) and global LS of right ventricle.

Peak RV longitudinal strain, which quantifies the maximal shortening in the $\mathrm{RV}$ free wall from apex to base, is likely to be a good estimator of RV function because $80 \%$ of the stroke volume is generated by longitudinal shortening of the RV free wall [11]. In the study of Gul et al. (2016), RV-free-S and RV-free-SR means were similar in the early period. Mean regional and mean RV free wall strain/strain rates observed at the one-month follow up were significantly increased compared to the pre-PCI period within each individual group [12].

In agreement with our results, the study of Elnoamany et al. (2014) assessed the strain of the RV free wall and showed statistically highly significant difference among the studied groups [13]. Consistent with our result Sachdev et al. (2011) have shown that noninvasive assessment of RV longitudinal systolic strain and strain rate independently predicts future right-sided heart failure and clinical deterioration [14].

Additionally, the study on the hand compared between studied groups regarding circumferential strain and revealed that there is highly statistically significant difference between them in all segments of right ventricle.

Hamada-Harimura et al. (2018) studied 692 patients hospitalized for acute decompensated HF with predischarge clinical, laboratory, and echocardiographic examinations, the latter including LV global longitudinal strain and LV global circumferential strain, and RV free wall strain (3 segments) and RV global 
longitudinal strain (free wall plus 3 septal segments). Echocardiographically, those with events had decreased free wall and global RV strain in addition to a larger left atrial volume index, more severe secondary mitral regurgitation, increased E/e', tricuspid regurgitant velocity, and inferior vena cava diameter, and lower tricuspid annular plane systolic excursion. Surprisingly, there were no differences in LV ejection fraction, LV global longitudinal strain and LV circumferential strain [15].

On the other hand, the present study found that $100 \%$ of patients had significant lesion in left anterior descending artery and only $31.4 \%$ had significant lesion in LCX (circumflex artery) while majority $68.6 \%$ had no Sig. Lesion by coronary angiography.

Finally, the present study assessed the correlation between the site of lesion and LAD and LCX artery with impaired right ventricle function and found that there is statistically significant difference between mid and apical segment of lateral wall and LAD; also there is statistically significant difference between apical segments of the septum, while there is statistically significant difference between anterior, lateral, inferior and regional parts of the right ventricle and circumflex artery.

Abdeltawab et al. (2019) found that patients with proximal or mid LCX lesions as well as patients with no reflow and worse procedural events to be correlated with RV dysfunction [16].

In the study of Medhat et al. (2016), they revealed that angiography revealed that RCA was the IRA in 96.7\% of RVMI patients and LCX was the IRA in 3.3\% of RVMI patients. This means that occlusion of the RCA proximal to the acute marginal branch suggests RVMI, while more proximal occlusions usually suggest more extensive necrosis of the posterior. In patients with left coronary artery dominance, a left circumflex coronary artery (LCX) occlusion may also be found [17].

Therefore, myocardial strain should be preferred to velocity information because it is less influenced by tethering effects and over all cardiac function. Nevertheless, Doppler-derived tissue velocity imaging, the most commonly used method for the assessment of LV strain, is angle dependent [18].

\section{Conclusions}

- Strain and strain rate imaging are feasible and reproducible tools in assessment of right ventricular function in patients with anterior ST segment elevated myocardial infarction (STEMI).

- Further attention should be given to the evaluation of RV function in post MI patients as it plays a significant role in patient symptomatology and a determinant of clinical outcome. Also septal contribution to RV function should be studied in more detail.

- More effort should be exerted in the near future to solve the technical problems and pitfalls of the strain and strain rate imaging. 


\section{Conflicts of Interest}

The authors declare no conflicts of interest regarding the publication of this paper.

\section{References}

[1] Vogel, B., Claessen, B.E., Arnold, S.V., Chan, D., Cohen, D.J., Giannitsis, E., et al. (2019) ST-Segment Elevation Myocardial Infarction. Nature Reviews Disease Primers, 5, 1-20. https://doi.org/10.1038/s41572-019-0090-3

[2] Naguib, T., Elsherbeiny, E., Elzayyat, A. and Tantawy, A. (2015) Predictors of Depressed Left Ventricular Function in Patients Presenting with ST-Elevation Myocardial Infarction. Zagazig University Medical Journal, 21, 1-18.

https://doi.org/10.21608/zumj.2015.4512

[3] Marcu, C.B., Beek, A.M. and Van Rossum, A.C. (2006). Cardiovascular Magnetic Resonance Imaging for the Assessment of Right Heart Involvement in Cardiac and Pulmonary Disease. Heart, Lung and Circulation, 15, 362-370.

https://doi.org/10.1016/j.hlc.2006.08.003

[4] Mertens, L.L. (2018) Echocardiographic Assessment of the Right Ventricle. In: Right Ventricular Physiology, Adaptation and Failure in Congenital and Acquired Heart Disease, Springer, Cham, 99-111. https://doi.org/10.1007/978-3-319-67096-6_9

[5] Voigt, J.U., Pedrizzetti, G., Lysyansky, P., Marwick, T.H., Houle, H., Baumann, R., et al. (2015) Definitions for a Common Standard for 2D Speckle Tracking Echocardiography: Consensus Document of the EACVI/ASE/Industry Task Force to Standardize Deformation Imaging. European Heart Journal-Cardiovascular Imaging, 16, 1-11. https://doi.org/10.1093/ehjci/jeu184

[6] Dandel, M., Lehmkuhl, H., Knosalla, C., Suramelashvili, N. and Hetzer, R. (2009) Strain and strain Rate Imaging by Echocardiography-Basic Concepts and Clinical Applicability. Current Cardiology Reviews, 5, 133-148. https://doi.org/10.2174/157340309788166642

[7] Thygesen, K., Alpert, J.S. and White, H.D. (2007) Universal Definition of Myocardial Infarction. Journal of the American College of Cardiology, 50, 2173-2195. https://doi.org/10.1016/j.jacc.2007.09.011

[8] Sima, A.V., Stancu, C.S. and Simionescu, M. (2009) Vascular Endothelium in Atherosclerosis. Cell and Tissue Research, 335, 191-203. https://doi.org/10.1007/s00441-008-0678-5

[9] Kowalski, M., Kukulski, T. and Jamal, F. (2001) Can Natural Strain and Strain Rate Quantify Regional Myocardial Deformation? A Study in Healthy Subjects. Ultrasound in Medicine and Biology, 27, 1087-1097. https://doi.org/10.1016/S0301-5629(01)00388-X

[10] Monaster, S.S., Ahmad, M.K. and Braik, A.G. (2014) Comparison between Strain and Strain Rate in Hypertensive Patients with and without Left Ventricular Hypertrophy: A Speckle-Tracking Study. Menoufia Medical Journal, 27, 322-328. https://doi.org/10.4103/1110-2098.141691

[11] Carlsson, M., Ugander, M. and Heiberg, E. (2007) The Quantitative Relationship between Longitudinal and Radial Function in Left, Right, and Total Heart Pumping in Humans. American Journal of Physiology: Heart and Circulatory Physiology, 293, 636-644. https://doi.org/10.1152/ajpheart.01376.2006

[12] Gul, I., Zungur, M., Aykan, A.C. and Gokdeniz, T. (2016) The Change in Right 
Ventricular Systolic Function According to the Revascularisation Method Used, Following Acute ST-Segment Elevation Myocardial Infarction. Cardiovascular Journal of Africa, 27, 37-44. https://doi.org/10.5830/CVJA-2015-077

[13] Elnoamany, M.F., Ahmed, N.F. and Ragab, E.M. (2014) Echocardiographic Assessment of Right Ventricular Function in Patients with Pulmonary Hypertension: Strain Imaging Study. Menoufia Medical Journal, 27,336-341.

https://doi.org/10.4103/1110-2098.141700

[14] Sachdev, A., Villarraga, H.R. and Frantz, R.P. (2011) Right Ventricular Strain for Prediction of Survival in Patients with Pulmonary Arterial Hypertension. Chest, 139, 1299-1309. https://doi.org/10.1378/chest.10-2015

[15] Hamada-Harimura, Y., Seo, Y., Ishizu, T., et al., for the ICAS-HF Investigators (2018) Incremental Prognostic Value of Right Ventricular Strain in Patients with Acute Decompensated Heart Failure. Circulation: Cardiovascular Imaging, 11, e007249. https://doi.org/10.1161/CIRCIMAGING.117.007249

[16] Abdeltawab, A.A., Elmahmoudy, A.M. and Elnammas, W. (2019) Assessment of right Ventricular Function after Successful Revascularization for Acute Anterior Myocardial Infarction without Right Ventricular Infarction by Echocardiography. Journal of the Saudi Heart Association, 31, 261-268. https://doi.org/10.1016/j.jsha.2019.07.001

[17] Ashmawy, M.M. and Yasser, H. (2016) Assessment of Right Ventricular Function in Acute Inferior Wall Myocardial Infarction in Patients Treated with Primary Percutaneous Coronary Intervention. Research Journal of Cardiology, 9, 8-16. https://doi.org/10.3923/rjc.2016.8.16

[18] Zehender, M., Kasper, W. and Kauder, E. (1993) Just H Right Ventricular Infarction as an Independent Predictor of Prognosis after Acute Inferior Myocardial Infarction. The New England Journal of Medicine, 328, 981-988.

https://doi.org/10.1056/NEJM199304083281401 